\section{Science and faith}

S1R-In seeking to refute the beliefs and arguments of creationists, J. Richard Wakefield (Nature 320, 392: 1986) makes four unjustified generalizations to which I must object as a Christian and as a scientist.

My first point deals with the limits to science. Wakefield states categorically that nothing is potentially beyond science. This is questionable. The scientific method is empirical and depends on testing one's hypotheses against what happens in the real world. Its conclusions ("scientific laws") are inductive and provisional, and they remain open to revision in the light of new and more comprehensive experience. Scientific knowledge is still partial and incomplete. and many things lie beyond its boundaries. The day may come when science can satisfactorily describe, predict and explain every phenomenon in the cosmos that can be subjected to scientific analysis; but the possibility that the universal set of real phenomena extends far beyond the finite subset of scientifically verifiable phenomena will remain and cannot be disproved by science. How can science ever illuminate what lies behind the beauty of form, of poetry, of music, of humour, and of human emotion? Humans are physical, rational, intuitive, emotional, personal, cultural, social, moral and spiritual beings. Science is only one of the forms of knowledge available to us; we are familiar with different kinds of knowledge in art, in love. in politics and in religion. Science is not served by making exaggerated claims on its behalf, any more than is creationism.

My second objection is to Wakefield's view of faith, which he defines as "belief without evidence". St Paul, however, taught that "faith gives substance to our hopes", faith is "the proving (or test) of things not seen" (Hebrews 11.1; New English Bible, Revised Standard Version - emphases mine). In the classical tradition of Christian experience and understanding, faith is trust that leads to action; and the outcome of living by faith, in the testimony of countless Christians, amply substantiates and justifies it. As science generally considers it good practice to test hypotheses before discarding them as invalid, I suggest that Wakefield and those who sympathize with his views subject mainstream scriptural Christian faith to the same test before they totally discount it.

Third, according to Wakefield, "we all know that science accepts nothing on faith". Science can provide us with statements about degrees of probability and correlation. To speak of the provisional and ever-cautious statements of science as if they were eternal proclamations of certainty and causality is to distort the truth.
As D.H. Koobs points out (Nature 319. $172 ; 1986)$. to assert today that the Universe and its life forms occurred spontaneously remains "clearly a matter of faith".

Finally, Wakefield claims that "creationists do their best to twist, lic. fabricate, misrepresent all they can of reality to deceive their followers and the lay public". While this may be true of some creationists, I cannot believe it is true of all. It is possible to hold a creationist view of the origin of life and the Universe with sincerity and intellectual integrity. And in the interests of scientific objectivity, it must be pointed out that scientists, too, have sometimes distorted the truth: let us remember Burt's obsessional prejudices about race and IQ which he dishonestly presented as if they were real experimental findings.

21 Mountsfield Court.

Hither Green Lane, London SEI3 6RR, UK

\section{Risk analysis}

SIR-S.O. Funtowicz and J.R. Ravetz (Nature 321, 644; 1986) are, of course, correct in writing that society must recognize that large improbable accidents can and will happen, whether they be collisions of Boeing 747 aircraft over Wembley Stadium during a Cup Final, or the failure of a nuclear power plant.

Their rejection of probabilistic risk analysis (PRA), however, is factually incorrect. It was not used in either of the two examples he cites - Three Mile Island or Chernobyl. In 1977, the US Nuclear Regulatory Commission instructed its staff not to use PRAs in the licensing procedures. As a result, nobody calculated for a Babcock-Wilcox reactor until the afternoon of 28 March 1979. If they had, the weakness of the operating procedure would have been quickly recognized and the accident at Three Mile Island avoided. In spite of numerous reports and discussions, both official and unofficial, nobody in the West has seen a PRA for Chernobyl. I do not believe that a complete one exists.

It is the procedure of thinking carefully about accidents, using logically plausible scenarios, that is our best and possibly our only defence against these scenarios occurring. This is what a PRA accomplishes.

Some responsible, competent person must have thought through the problem enough to derive a number with its uncertainty. Whether Funtowicz and Ravetz believe the number is comparatively irrelevant. But they should not discourage the procedure itself, which is almost the only procedure that we have.

RichaRD WILSON

Department of Physics,

Harvard University,

Cambridge, Massachusetts 02138, USA

\section{Pesticide regulation}

SiR-1 appreciated Kenneth Mellanby's letter in Nature $(321,465 ; 1986)$ about my objection (Nature 320, 391; 1986) to a sentence in Lord Ashby's review of John Sheail's book (Nature 318, 21; 1985).

I have admired the British method of pesticide regulation, and Sheail performed a good service by describing the collaboration there between industry and government.

I certainly did not intend to imply that it was Mellanby's British colleagues who resorted to "such unscientific methods as deliberately distorting or omitting all the data that refuted their (anti-DDT) allegations". Instead I had in mind only the work of several notorious US scientists, especially some employees of our federal Fish and Wildlife Service and a few in the California Department of Fish and Game. Their statements were frequently published, without competent peer review, in magazines such as Science. BioScience, Scientific American and various "bird" journals. Specific refutations of their allegations have been published elsewhere by many concerned US scientists. but were ignored by the US Environmental Protection Agency (EPA).

EPA joined the attack. and sought to direct a worldwide condemnation of agrichemicals and chemicals used to alleviate insect-borne disease outbreaks, via its Toxic Substances Control Act (TSCA). In response, British Science Attaché Alan Smith was applauded by over 600 specialists at a meeting called by EPA to discuss the act when he stated: "This draft is like the jabberwocky of Lewis Carroll ... . the language of chemistry mixes uneasily with the language of metaphysics and the overlay of legal jargon makes the whole incomprehensible." After calling it an "absurd piece of gobbledegook". Smith suggested that EPA should "not presume to legislate for the Universe and the whole human race" and that "there is a limit to the number of times even the greatest country in the world can afford to appear ridiculous in international affairs" (Science 196, 1182-83; 1977).

Although DDT is no longer used in the United States, false claims about it continue to be repeated. The reasons are varied, but are well-known. The same sort of campaign that succeeded in banning DDT has more recently been directed against 2,4.5-T. malathion. DES and many other useful chemicals of very slight hazard to man or the environment. Unless the scientific community actively exposes such false statements as have been made in journals and indicates disapproval of those who deliberately make them. the human race faces a very bleak future.

San Jose State University. J. Gordon Edwards

San, Jose, California 95192, USA 